\title{
The impact of disease severity, illness beliefs and coping strategies on outcomes in psoriatic arthritis
}

DOI:

10.1002/acr.23330

\section{Document Version}

Accepted author manuscript

Link to publication record in Manchester Research Explorer

\section{Citation for published version (APA):}

Howells, L., Chisholm, A., Cotterill, S., Chinoy, H., Warren, R. B., \& Bundy, C. (2018). The impact of disease severity, illness beliefs and coping strategies on outcomes in psoriatic arthritis. Arthritis Care and Research, 70(2), 295-302. https://doi.org/10.1002/acr.23330

\section{Published in:}

Arthritis Care and Research

\section{Citing this paper}

Please note that where the full-text provided on Manchester Research Explorer is the Author Accepted Manuscript or Proof version this may differ from the final Published version. If citing, it is advised that you check and use the publisher's definitive version.

\section{General rights}

Copyright and moral rights for the publications made accessible in the Research Explorer are retained by the authors and/or other copyright owners and it is a condition of accessing publications that users recognise and abide by the legal requirements associated with these rights.

\section{Takedown policy}

If you believe that this document breaches copyright please refer to the University of Manchester's Takedown Procedures [http://man.ac.uk/04Y6Bo] or contact uml.scholarlycommunications@manchester.ac.uk providing relevant details, so we can investigate your claim.

\section{OPEN ACCESS}


Article type : Original Article

\section{Running header title: Predicting outcomes in psoriatic arthritis}

Title: The impact of disease severity, illness beliefs and coping strategies on outcomes in psoriatic arthritis.

Authors: Laura Howells ${ }^{1} \mathrm{MSc}$, Anna Chisholm ${ }^{1,3} \mathrm{PhD}$, Sarah Cotterill ${ }^{2} \mathrm{PhD}$, Hector Chinoy ${ }^{1,4}$ PhD FRCP, Richard B Warren ${ }^{1}$ MD PhD, Christine Bundy ${ }^{1,3}$ PhD, AFBPS

Affiliations: ${ }^{1}$ Manchester Centre for Dermatology Research; ${ }^{2}$ Centre for Biostatistics; ${ }^{3}$ Manchester Centre for Health Psychology, ${ }^{4}$ National Institute of Health Research Manchester Musculoskeletal Biomedical Research Unit, Central Manchester University Hospitals NHS Foundation Trust (all University of Manchester, Manchester, UK)

Corresponding author: Prof. Christine Bundy, Room 7, 13th Floor, Eastgate House, 35-43 Newport Road, Cardiff. CF24 0AB, bundyec@cardiff.ac.uk, Tel: +44 (0)29 20687842

Financial disclosures: Laura Howells and Sarah Cotterill have no conflicts of interest. Anna Chisholm has acted as adviser or speaker for Abbvie, Janssen and Celgene. Christine Bundy has acted as adviser or speaker for Abbvie, Celgene, Johnson \& Johnson, Novartis. Hector Chinoy has acted as adviser or speaker for Abbvie, Celgene, Johnson \& Johnson, Novartis, This article has been accepted for publication and undergone full peer review but has not been through the copyediting, typesetting, pagination and proofreading process, which may lead to differences between this version and the Version of Record. Please cite this article as doi: 10.1002/acr.23330

This article is protected by copyright. All rights reserved. 
Pfizer, Roche, UCB. Richard B Warren has acted as adviser or speaker for Abbvie, Amgen, Almirall, Celgene, Novartis, Pfizer, UCB, Leo, Janssen, Lilly and Xenoport. None of the authors received funding for this study.

\begin{abstract}
Objectives: Little is known about how people with psoriatic arthritis (PsA) cope and manage their condition, but data show psychological problems are under-recognised and under-treated. The Common Sense - Self-Regulatory Model (CS-SRM) suggests illness beliefs, mediated by coping, may influence health outcomes. The study aimed to investigate the roles of disease severity, illness beliefs and coping strategies in predicting depression, anxiety and QoL in people with PsA. Additionally, we aimed to assess the role of depression and anxiety in predicting QoL.
\end{abstract}

Methods: A cross-sectional observational study where adults with PsA ( $N=179)$ completed validated measures of predictor (illness beliefs, coping strategies, disease severity) and outcome variables (depression, anxiety, QoL) using an online survey distributed via social media.

Results: The participants were a community sample of 179 adults with PsA aged 20 to 72 ( $77.1 \%$ female). After controlling for disease severity, hierarchical multiple regression models indicated that more negative beliefs about consequences and behavioural disengagement as a coping method predicted levels of depression and self-blame predicted anxiety. Beliefs about consequences and the presence of depression predicted quality of life scores after controlling for disease severity.

This article is protected by copyright. All rights reserved. 
Conclusions: This study offers support for the use of the CS-SRM in explaining variation on psychological outcomes in individuals with PsA. The illness beliefs and coping strategies identified as predictors in this paper are potential targets for interventions addressing PsA-related distress and QoL.

Keywords: Psoriatic arthritis, depression, anxiety, quality of life, coping, illness beliefs, disease severity

\section{Significance and Innovations}

- This is the first quantitative research project to examine the role of Illness beliefs and coping strategies in predicting depression, anxiety and QoL in individuals with PsA.

- The illness beliefs and coping strategies identified as predictors may be useful targets for psychological interventions in individuals with PsA.

- Holistic management of PsA should take into account people's beliefs about PsA and associated coping strategies.

\section{Introduction}

Psoriasis is a chronic, inflammatory skin condition characterised by desquamation (skin peeling), pruritus (skin itching) and pain (1). The associated condition PsA is characterised by joint inflammation that has been described as having five major clinical patterns; distal, oligoarticular, polyarticular, primarily axial, and arthritis mutilans (2).

This article is protected by copyright. All rights reserved. 
However, these patterns are not always useful in practice as the clinical pattern of the disease changes over time (2). PsA is generally considered to involve peripheral arthritis, axial disease, enthesitis, dactylitis, and skin and nail disease (2). PsA affects up to approximately $30 \%$ of people living with psoriasis (3).

Both psychological distress (comprising depression and anxiety) and reduced quality of life (QoL) have been identified as under-recognised and under-managed aspects of PsA (4). Higher levels of depression and anxiety have been found in people with PsA and psoriasis than in people with psoriasis alone (5). One review has suggested the emotional burden of PsA is higher than other arthritic conditions (6). Levels of QoL in psoriasis patients are comparable with other serious long-term conditions including cancer and heart disease and people with PsA reported poorer QoL than people with psoriasis alone $(7,8)$. Given that people with PsA tend to experience low quality of life and levels of anxiety and depression beyond that observed in people with psoriasis and people with other arthritic conditions, investigation into the specific factors driving these outcomes in people with PsA is warranted. Identifying these factors could inform psychological interventions tailored to people living with PsA.

The relationship between psychological outcomes and disease severity in PsA is not straightforward. For instance, research comparing rheumatoid arthritis (RA) and PsA found RA patients reported greater disease severity, but PSA patients encountered more bodily pain and more significant role limitations due to emotional problems (9). Since PsA patients often have comorbid psoriasis, this may be due to the cumulative impact of skin and joint disease that is not yet well understood $(10,11)$. Furthermore, disease severity in combination with fears of negative evaluation predicted distress and QoL in psoriasis

This article is protected by copyright. All rights reserved. 
patients (12). Therefore, psychological outcomes in people with PsA are likely to be related both to disease severity and other psychological factors.

The Common Sense Self-Regulatory Model (CS-SRM; Leventhal, Meyer, \& Nerenz, 1980) suggests illness beliefs (e.g. about the cause, consequences, identity, duration and controllability of the illness) play a vital role in both physical and psychological adjustment to illness (13). These five core illness beliefs inform coping strategies, which in turn leads to the appraisal of coping success, and ultimate adjustment to illness (13). However, in conditions including RA and psoriasis, illness beliefs explain variance in clinical outcomes that are not mediated by coping strategies (14-16). For example, coping strategies failed to account for variance in physical function, pain and depression in RA patients, whereas illness beliefs accounted for a significant proportion of variance for all three outcomes (14).

There has been limited research on the beliefs people with PsA hold about their illness and how these beliefs may affect patient outcomes. Qualitative research suggests individuals with PsA can hold unfounded and potentially unhelpful beliefs about the progression of their condition (4). It is plausible that addressing these negative expectations in consultations may alleviate distress. In psoriasis, illness beliefs have been shown to be the most consistent variables accounting for psoriasis-related stress, distress and disability when compared to coping strategies, alexithymia (inability to express one's feelings), age, gender, clinical severity and worry (17). Illness beliefs have also been found to contribute to health-related quality of life (HRQOL) (18). The extent to which these types of beliefs account for distress in people with PsA remains unknown.

This article is protected by copyright. All rights reserved. 
Illness places internal and external demands on an individual's resources for coping and self-management strategies to deal with these demands can be both cognitive and behavioural (19). The CS-SRM explains how illness beliefs influence coping methods, which in turn influences psychological and physical adaptation to illness. Therefore, coping strategies and associated beliefs about illness may be important in understanding lived experiences of PsA-related distress. A qualitative study reported patients resigned themselves to living with the disease, resulting in avoidance/distraction coping strategies that included methods of escapism such as alcohol use, self-medication with painkillers and sleeping pills and comfort eating (4). The continued suppression of thoughts related to the disease via use of these coping strategies are likely to be playing a role in maintaining distress (20).

Furthermore, previous studies in patients with different rheumatic conditions have resulted in equivocal results regarding whether depression and anxiety predict quality of life outcomes. Depression but not anxiety has been found to predict physical HRQOL in RA patients, only illness concern but not depression or anxiety predicted physical HRQOL in Ankylosing Spondylitis and, anxiety but not depression, was a predictor of physical HRQOL in PsA patients $(18,21)$. There needs to be further exploration of how depression and anxiety levels predict quality of life in people with PsA.

\section{Research aims and hypotheses}

We aimed to investigate the roles of disease severity, illness beliefs and coping strategies in predicting depression, anxiety and QoL in people with PsA. Additionally, we aimed to assess the role of depression and anxiety in predicting QoL. We hypothesised that illness beliefs (perceived higher consequences, lower treatment control, lower personal

This article is protected by copyright. All rights reserved. 
control, higher concern, less coherence, longer timeline) and greater use of coping strategies (more use of behavioural disengagement, more use of self-blame, more use of substance use and more use of denial) would be related to all three outcomes (higher depression, higher anxiety and lower QoL), after controlling for disease severity. We also predicted that higher depression and anxiety scores would be related to lower QoL.

\section{Methods}

\section{Participants}

Adults with PsA were recruited using social media platforms (originally posted by The UK and NI Psoriasis Association, Manchester Skin Research, Psoriasis Shout Out and retweeted by others), website links (University of Manchester Skin Research webpage and the Psoriasis Association), and posters/flyers at the University of Manchester and Salford Royal Hospital. Participants were invited to take part if they met the inclusion criteria: selfreported diagnosis of PsA by a doctor and self-reported as $\geq 18$ years old. Patients were not included if they met the exclusion criteria: self-reported memory problems, another medical condition (other than psoriasis) or a psychiatric condition. All participants were recruited on a voluntary basis. Informed consent was obtained from all participants prior to completing the survey.

\section{Procedure}

Participants were directed to a webpage on www.surveymonkey.com containing the Participant Information Sheet. If they wished to continue they proceeded to an online consent form. Progress was dependent on completion of the consent form. Participants completed the measures online.

This article is protected by copyright. All rights reserved. 


\section{Measures}

Participants reported their age (years), sex (male or female), height (feet and inches), weight (stones and pounds, which was converted into kg to calculate Body Mass Index (BMI)), duration since PsA diagnosis (years) and smoking (number of cigarettes per week). The Hospital Anxiety and Depression Scale (HADS) was used to measure anxiety (7 items) and depression (7 items) (22). A score $\geq 8$ indicates a probable case of depression or anxiety and a score $>10$ indicates a definite case (23). Quality of life was measured using the Psoriatic Arthritis Quality of Life (PSAQoL) questionnaire which contains 20 items with binary true/not true scoring where higher scores indicate lower QoL (24). Seven items from the Brief Illness Perception Questionnaire (B-IPQ) were used: consequences, timeline, identity, personal control, treatment control, coherence and concern (25). Emotional representations were measured by the HADS. Four subscales ( 2 items per subscale) from the Brief COPE were used: behavioural disengagement, self-blame, substance use and denial (19). We used a qualitative study exploring predictors of distress in PSA patients to select coping strategies relevant to this patient group that mapped most closely to the Brief COPE subscales (4). Preliminary correlation analysis also supported use of these subscales. Psoriasis severity was measured using the self-assessment Simplified Psoriasis Index (sa-SPI), which is a weighted index of the extent of psoriasis on 10 unequal areas and a plaque severity item (1). PsA severity was measured using the patient global assessment "Considering all the ways your arthritis affects you, how are you feeling today?" (5-point Likert scale from "very good, no symptoms, no limitations on normal activities" to "very poor, very severe symptoms which are intolerable, inability to carry out normal activities") from the Psoriatic Arthritis Response Criteria (PSARC) (26). Consideration was given to instrument utility including which had

This article is protected by copyright. All rights reserved. 
recognised validity and reliability; which best measures the concepts; which were currently used in clinical practice in the UK and the length of the overall questionnaire.

\section{Statistical analysis}

There was little previous work on which to base a precise power calculation, therefore we used the heuristic of the number of variables being examined multiplied by 10 to determine the sample size. The strength of the relationship between the outcomes and the independent variables was estimated using Spearman's Rho and Pearson's correlation coefficients, as appropriate. Items with a fair degree of correlation with outcome variables $(r$ $\geq .3$ or $\rho \geq .3$ ) were considered for inclusion in hierarchical multiple linear regression (Table 1) and the assumptions of multiple linear regression were met.

The final hierarchical multiple regression models were built separately for each of the three outcomes - depressions, anxiety and quality of life, based on the theoretical underpinnings of the CS-SRM. Step 1 included severity measures of psoriasis and PSA (the sa-SPI and PSARC respectively) to control for disease severity. Preliminary analyses (t-test and correlation) were conducted to explore whether sex, age or disease duration should also be controlled for but none were associated with the outcomes.

For each model, in a stepped approach the appropriate illness beliefs were added, followed by the appropriate coping strategies. In the model with QoL as the outcome, at the final step the appropriate anxiety and depression measure were added. The model building aimed to identify specific beliefs, coping strategies, and for the outcome QoL also distress variables, that may be particularly important for the high psychological morbidity seen in this population. The aim was to produce a simple model including only illness beliefs, coping

This article is protected by copyright. All rights reserved. 
strategies (and for QoL also distress variables) that were relevant to the outcome. Initially, all items that correlated above 0.3 were included in the regression models, however as each step was added to the model, the regression coefficients were re-examined and any variables that did not correlate over 0.3 were removed from the analysis. Pairwise deletion was used to manage missing data. Data imputation was not used because data were not considered to be randomly missing.

\section{Ethical Approval}

This study is in compliance with the Helsinki Declaration and was approved by the University of Bath's Department of Psychology ethics committee [Ref: 15-083] and the University of Manchester's UREC ethics committee [Ref: 15260].

\section{Results}

\section{Participant characteristics}

201 people were recruited to the survey, but 22 were not included in this study as they did not complete any of the main variables. Of the remaining 179 participants, $77.1 \%$ were female, all with self-reported PsA. Age ranged from 20 to 72 years ( $M=45.41, S D=$ 10.41). Table 2 shows how sex and age of this sample compares to those with PsA identified in a UK population-based study using The Health Improvement Network (THIN) (27). This sample has a higher proportion of females than the population-based study and a lower proportion of older aged participants. The mean BMI was $29.6 \mathrm{~kg} / \mathrm{m}^{2}$ (SD 7.02) and $63.5 \%$ of participants were overweight or obese (28). Participants ranged from being diagnosed less than one month to 42 years with a mean disease duration of 7 years (SD 7.6). The majority of participants were non-smokers (82\%), but $11 \%$ were smoking over 30 cigarettes per day.

This article is protected by copyright. All rights reserved. 
On the HADS anxiety subscale, $60.8 \%$ of participants scored $\geq 8$ and $46.8 \%$ scored $\geq 10$. On the depression subscale, $51.2 \%$ scored $\geq 8$ and $38.8 \%$ scored $\geq 10$. The mean, standard deviation (or median and inter-quartile range for variables with a non-normal distribution), maximum and minimum scores of all variables are summarised in Table 3.

\section{Depression}

In the final model predicting depression, disease severity was controlled for on entry to step 1, beliefs about consequences was entered at step 2 and behavioural disengagement was entered at step 3 (Table 4). At step 3, where all variables were modelled together, there was a statistically significant increase in depression scores in participants with more severe PsA, a rise of $0.70(95 \% \mathrm{Cl} 0.03,1.35)$ for each unit rise in disease severity. There was no statistically significant increase in levels of depression relating to psoriasis severity. After controlling for disease severity, the model indicated that levels of depression increased by $0.58(95 \% \mathrm{Cl} 0.27,0.90)$ with each unit rise in beliefs about consequences and by $0.94(95 \%$ $\mathrm{Cl} 0.58,1.31$ ) with each unit rise in behavioural disengagement.

\section{Anxiety}

In the final model predicting anxiety, disease severity was controlled on entry to the first step, no illness belief variables were included because they did not meet the criteria for inclusion. Self-blame was entered at step 2 (Table 4). There was no statistically significant difference in the levels of anxiety based on participants levels of PsA severity or psoriasis severity. Levels of anxiety increased $1.26(95 \% \mathrm{Cl} 0.91,1.62)$ with each unit rise in selfblame.

This article is protected by copyright. All rights reserved. 


\section{QoL}

In the final model predicting QoL, disease severity was entered at step 1, beliefs about consequence were entered at step 2 and depression was entered at step 3 (Table 4). There was not a statistically significant increase in scores on the PsAQoL related to PsA severity or psoriasis severity. After controlling for disease severity, PsAQoL scores increased by $0.83(95 \% \mathrm{Cl} 0.50,1.16)$ with each unit rise in beliefs about consequences and increased by $0.64(95 \% \mathrm{Cl} 0.48,0.80)$ with each unit rise in depression.

\section{Discussion}

The results suggest high rates of distress in this sample and greater rates of depression and anxiety than has been found in previous PsA studies. Probable 'cases' of depression, were $60.8 \%$ and anxiety $51.2 \%$, whilst a previous study by McDonough et al. showed $36.6 \%$ and $22.3 \%$ respectively (5). It has been identified that there are unmet needs for psoriasis patients and the high level of distress identified here highlights there are unmet need for distress management within this PsA population (29).

Illness beliefs and coping strategies are a promising target for holistic management of PsA, the person-centred approach which assesses and manages medical, psychological and social factors. We showed beliefs about the consequences of their PsA and the use of behavioural disengagement independently predicted depression scores after controlling for disease severity. Similarly, self-blame independently predicted anxiety scores after controlling for disease severity.

QoL was predicted by beliefs about the consequences of their PsA and depression after controlling for disease severity. In previous studies that assessed the role of anxiety,

This article is protected by copyright. All rights reserved. 
depression and illness perceptions in predicting physical HRQOL in rheumatic conditions, depression but not anxiety has been found to predict physical HRQOL in RA patients, only illness concern but not depression or anxiety predicted physical HRQOL in Ankylosing Spondylitis and, anxiety but not depression, was a predictor of physical HRQOL in PsA patients $(18,21)$. Therefore, the results of this study are more in line with factors that predicted QoL in RA patients rather than PsA patients in previous studies. Clearly further work is needed to unpick the influential psychological factors predicting QoL in PsA.

Individuals do not hold discrete illness beliefs but rather experience them as part of a schema of illness (30). Therefore, it may be that some beliefs were not strong individual predictors of outcomes in this study and in the study by Kotsis et al. because they correlated with other beliefs that were stronger predictors. Further research is required to test the potential impact of more complex clustering of illness beliefs on these outcomes.

Previous qualitative research found distress in PsA was accompanied by unhelpful beliefs and avoidance coping strategies (4). This study supports that beliefs regarding consequences of the illness, behavioural disengagement and self-blame may contribute to distress. Unlike the qualitative study, participants reported relatively low use of behavioural disengagement, denial and substance use with validated measures. These discrepancies may be due to sample differences; this study sampled a community group reporting a range of severities and disease duration compared with the previous study where patients were recruited from tertiary care and had complex disease histories (4). Nevertheless, use of specific coping strategies predicted psychological outcomes and can be used to identify the patients most in need of psychological support.

This article is protected by copyright. All rights reserved. 
PsA is a chronic, relapsing condition, therefore a belief of a long timeline, as measured in this study, may not indicate how well the individual is adapting to the disease and beliefs regarding a cyclical (varying) timeline may be a more helpful construct for predicting distress and QoL in PsA which is characterised by flares which also involve psychological symptoms and loss of normal functioning $(31,32)$. A belief that flaring is likely to occur more frequently has been linked to higher distress in other illness populations (33).

PsA severity did not account for important variation in depression, anxiety and quality of life in the final models contradicting a previous study that found both depression and anxiety were associated with higher levels of joint inflammation in patients with PsA (5). Whilst the potential role disease severity can play should not be dismissed, it is important to note that other factors, including beliefs and coping strategies may provide a more reliable indicator of which patients are not adapting well to their illness. Psoriasis severity did not correlate at all with distress outcomes contrary to previous literature suggesting disease severity in psoriasis is associated with distress (12). This finding may be due to our focus on PsA rather than psoriasis alone in this study. The finding that PsA severity was related to distress whilst psoriasis severity was not, highlights the importance of considering the context of an individual's multiple health conditions when treating a disease. By not considering other health conditions, healthcare professionals may miss how these contribute to distress in patients.

\section{Strengths and Limitations}

The cross-sectional nature of this study means that causality cannot be inferred.

However, based on the CS-SRM, we can assume this is a dynamic process with bi-directional relationships between distress, beliefs and coping (13).

This article is protected by copyright. All rights reserved. 
We aimed to recruit a representative sample of PsA patients. The advantage of recruitment via social media is the potential to recruit across countries. However, participants recruited via social media are a self-selecting sample who may not represent all individuals with PsA. Older people were under-represented in our sample, which may have been due to the online nature of the study. Our study also contained a higher proportion of females than the UK population-based sample, although preliminary analyses found no gender differences in the outcomes. Furthermore, since recruitment was predominantly via UK and US based charities, poster and flyer recruitment was in the UK only and participants had to be English speaking; caution must be taken when generalising these results to other populations. We were reliant on participants self-reporting PsA diagnosed by their doctor, so we cannot be confident of the clinical diagnosis of PsA.

In the context of this exploratory study, consideration was given to responder burden and brief measures were used where possible. Single-item measures are less sensitive than multi-item measures and future in-depth studies may need to consider using more reliable measures such as the full length IPQ-R instead of the brief version (B-IPQ).

The confidence intervals suggest the changes in outcomes predicted by the B-IPQ and the Brief COPE items were quite small indicating a reasonably narrow and precise estimate of the role of these factors. Future research should indicate what constitutes a meaningful change on the HADS scale in this population in order to improve the interpretation of this and future studies.

This article is protected by copyright. All rights reserved. 


\section{Conclusions: Future directions for research and practice}

Longitudinal studies are needed to establish the direction of relationships between PsA outcomes and psychological factors. We recommend clinician-derived severity measures be used alongside patient self-report measures to establish the relationship between disease severity and psychological outcomes (34). Illness beliefs, coping strategies and severity are not likely to be the only factors related to psychological outcomes in people with PsA and further exploration, including qualitative approaches, would provide greater insight.

Holistic management of PsA requires comprehensive assessment including distress, beliefs and coping. Some have argued due to limited resources, interventions in this population should be pragmatic and cost-effective (35). We assert it may be beneficial in the long-term for clinicians to spend time addressing patient's unhelpful beliefs and coping strategies and using the B-IPQ is a pragmatic way for clinicians to begin discussions surrounding patient beliefs.

This study provides support for the usefulness of the CS-SRM in explaining factors related to psychological distress in a PsA sample and provides a basis for intervention to improve PsA-related distress. Interventions to change beliefs about consequences of the illness, self-blame and behavioural disengagement may improve distress associated with PsA.

This article is protected by copyright. All rights reserved. 


\section{Acknowledgements}

The research team would like to thank Dr Julie Turner-Cobb who was the academic supervisor of Laura Howells for this project during her MSc placement. They would also like to thank the organisations and individuals who helped us with recruitment and all the individuals who participated in this research. This publication was supported by researchers at the National Institute for Health Research (NIHR) Biomedical Research Unit Funding Scheme and the University College London Hospitals Biomedical Research Centre. The views expressed are those of the authors and not necessarily those of the (UK) National Health Service (NHS), the NIHR or the (UK) Department of Health.

\section{References}

1. Chularojanamontri L, Griffiths CE, Chalmers RJ. The Simplified Psoriasis Index (SPI): a practical tool for assessing psoriasis. The Journal of investigative dermatology. 2013;133(8):1956-62. 2. Gladman DD. Clinical Features and Diagnostic Considerations in Psoriatic Arthritis. Rheumatic diseases clinics of North America. 2015;41(4):569-79.

3. Zachariae H. Prevalence of joint disease in patients with psoriasis. American Journal of Clinical Dermatology, 4(7). 2003:441-7.

4. Chisholm A, Pearce CJ, Chinoy H, Warren RB, Bundy C. Distress, misperceptions, poor coping and suicidal ideation in psoriatic arthritis: a qualitative study. Rheumatology (Oxford, England). 2016. 5. McDonough E, Ayearst R, Eder L, Chandran V, Rosen CF, Thavaneswaran A, et al. Depression and anxiety in psoriatic disease: prevalence and associated factors. The Journal of rheumatology. 2014;41(5):887-96.

6. Lee S, Mendelsohn A, Sarnes E. The burden of psoriatic arthritis: a literature review from a global health systems perspective. $P \& T$ : a peer-reviewed journal for formulary management. 2010;35(12):680-9.

7. Rapp SR, Feldman SR, Exum ML, Fleischer AB, Jr., Reboussin DM. Psoriasis causes as much disability as other major medical diseases. Journal of the American Academy of Dermatology. 1999;41(3 Pt 1):401-7.

8. Rosen CF, Mussani F, Chandran V, Eder L, Thavaneswaran A, Gladman DD. Patients with psoriatic arthritis have worse quality of life than those with psoriasis alone. Rheumatology (Oxford, England). 2012;51(3):571-6.

9. Husted JA, Gladman DD, Farewell VT, Cook RJ. Health-related quality of life of patients with psoriatic arthritis: a comparison with patients with rheumatoid arthritis. Arthritis and rheumatism. 2001;45(2):151-8.

This article is protected by copyright. All rights reserved. 
10. Kimball AB, Gieler U, Linder D, Sampogna F, Warren RB, Augustin M. Psoriasis: is the impairment to a patient's life cumulative? Journal of the European Academy of Dermatology and Venereology : JEADV. 2010;24(9):989-1004.

11. Warren RB, Kleyn CE, Gulliver WP. Cumulative life course impairment in psoriasis: patient perception of disease-related impairment throughout the life course. The British journal of dermatology. 2011;164 Suppl 1:1-14.

12. Leary MR, Rapp SR, Herbst KC, Exum ML, Feldman SR. Interpersonal concerns and psychological difficulties of psoriasis patients: effects of disease severity and fear of negative evaluation. Health psychology : official journal of the Division of Health Psychology, American Psychological Association. 1998;17(6):530-6.

13. Leventhal H, Meyer D, Nerenz D. The common sense representation of illness danger. Contributions to medical psychology. 1980;2:7-30.

14. Groarke A, Curtis R, Coughlan R, Gsel A. The role of perceived and actual disease status in adjustment to rheumatoid arthritis. Rheumatology (Oxford, England). 2004;43(9):1142-9.

15. Scharloo M, Kaptein AA, Weinman J, Hazes JM, Willems LN, Bergman W, et al. Illness perceptions, coping and functioning in patients with rheumatoid arthritis, chronic obstructive pulmonary disease and psoriasis. Journal of psychosomatic research. 1998;44(5):573-85.

16. Moss-Morris R, Petrie KJ, Weinman J. Functioning in chronic fatigue syndrome: do illness perceptions play a regulatory role? British Journal of Health Psychology. 1996;1(1):15-25.

17. Fortune DG, Richards HL, Griffiths CE, Main CJ. Psychological stress, distress and disability in patients with psoriasis: consensus and variation in the contribution of illness perceptions, coping and alexithymia. The British journal of clinical psychology / the British Psychological Society. 2002;41(Pt 2):157-74.

18. Kotsis K, Voulgari PV, Tsifetaki N, Machado MO, Carvalho AF, Creed F, et al. Anxiety and depressive symptoms and illness perceptions in psoriatic arthritis and associations with physical health-related quality of life. Arthritis care \& research. 2012;64(10):1593-601.

19. Carver CS. You want to measure coping but your protocol's too long: consider the brief COPE. International journal of behavioral medicine. 1997;4(1):92-100.

20. Wegner DM, Zanakos S. Chronic thought suppression. Journal of personality. 1994;62(4):616-40.

21. Hyphantis T, Almyroudi A, Paika V, Degner LF, Carvalho AF, Pavlidis N. Anxiety, depression and defense mechanisms associated with treatment decisional preferences and quality of life in nonmetastatic breast cancer: a 1-year prospective study. Psycho-oncology. 2013;22(11):2470-7.

22. Zigmond AS, Snaith RP. The hospital anxiety and depression scale. Acta psychiatrica Scandinavica. 1983;67(6):361-70.

23. Snaith RP. The Hospital Anxiety And Depression Scale. Health and quality of life outcomes. 2003;1:29.

24. McKenna SP, Doward LC, Whalley D, Tennant A, Emery P, Veale DJ. Development of the PsAQoL: a quality of life instrument specific to psoriatic arthritis. Annals of the rheumatic diseases. 2004;63(2):162-9.

25. Broadbent E, Petrie KJ, Main J, Weinman J. The brief illness perception questionnaire. Journal of psychosomatic research. 2006;60(6):631-7.

26. Clegg DO, Reda DJ, Mejias E, Cannon GW, Weisman MH, Taylor T, et al. Comparison of sulfasalazine and placebo in the treatment of psoriatic arthritis. A Department of Veterans Affairs Cooperative Study. Arthritis and rheumatism. 1996;39(12):2013-20.

27. Ogdie A, Langan S, Love T, Haynes K, Shin D, Seminara N, et al. Prevalence and treatment patterns of psoriatic arthritis in the UK. Rheumatology (Oxford, England). 2013;52(3):568-75.

28. Organization WH. BMI classifications. WHO, Geneva. 2006.

29. Nelson PA, Chew-Graham CA, Griffiths CE, Cordingley L. Recognition of need in health care consultations: a qualitative study of people with psoriasis. The British journal of dermatology. 2013;168(2):354-61.

This article is protected by copyright. All rights reserved. 
30. Clatworthy J, Hankins M, Buick D, Weinman J, Horne R. Cluster analysis in illness perception research: A Monte Carlo study to identify the most appropriate method. Psychology and Health. 2007;22(2):123-42.

31. Petrie KJ, Weinman J. Why illness perceptions matter. Clinical medicine (London, England). 2006;6(6):536-9.

32. Moverley AR, Vinall-Collier KA, Helliwell PS. It's not just the joints, it's the whole thing: qualitative analysis of patients' experience of flare in psoriatic arthritis. Rheumatology (Oxford, England). 2015;54(8):1448-53.

33. Moss-Morris R, Weinman J, Petrie K, Horne R, Cameron L, Buick D. The revised illness perception questionnaire (IPQ-R). Psychology and health. 2002;17(1):1-16.

34. Chaudhry SR, Thavaneswaran A, Chandran V, Gladman DD. Physician scores vs patient selfreport of joint and skin manifestations in psoriatic arthritis. Rheumatology (Oxford, England). 2013;52(4):705-11.

35. Burden AD, Hilton Boon M, Leman J, Wilson $H$, Richmond R, Ormerod AD. Diagnosis and management of psoriasis and psoriatic arthritis in adults: summary of SIGN guidance. BMJ (Clinical research ed). 2010;341:c5623.

Table 1

Correlations between psychological outcomes (depression, anxiety and quality of life), and potential predictor variables (disease severity, illness beliefs, and coping strategies)

\begin{tabular}{|c|c|c|c|c|c|}
\hline & \multicolumn{2}{|c|}{ Depression } & \multicolumn{2}{|c|}{ Anxiety } & \multirow{2}{*}{$\begin{array}{l}\text { Quality of Life } \\
\rho \\
(\mathrm{N})\end{array}$} \\
\hline & $\begin{array}{l}R \\
(\mathrm{~N})\end{array}$ & $\begin{array}{l}\rho \\
(\mathrm{N})\end{array}$ & $\begin{array}{c}R \\
(\mathrm{~N})\end{array}$ & $\begin{array}{l}\rho \\
(\mathrm{N})\end{array}$ & \\
\hline Psoriasis severity & & $\begin{array}{l}.15 \\
(139)\end{array}$ & & $\begin{array}{l}.19 * \\
(140)\end{array}$ & $\begin{array}{l}.09 \\
(135)\end{array}$ \\
\hline PsA severity & $\begin{array}{l}.48^{*} \\
(155)\end{array}$ & & $\begin{array}{l}.27^{*} \\
(156)\end{array}$ & & $\begin{array}{l}.54^{*} \\
(150)\end{array}$ \\
\hline Consequences & & $\begin{array}{l}.55^{*} \\
(160)\end{array}$ & & $\begin{array}{l}.32 * \\
(161)\end{array}$ & $\begin{array}{l}.64^{*} \\
(149)\end{array}$ \\
\hline Timeline & & $\begin{array}{l}.10 \\
(160)\end{array}$ & & $\begin{array}{l}.06 \\
(161)\end{array}$ & $\begin{array}{l}.13 \\
(149)\end{array}$ \\
\hline Personal control & & $\begin{array}{l}-.22^{*} \\
(160)\end{array}$ & & $\begin{array}{l}-.12 \\
(161)\end{array}$ & $\begin{array}{l}-.24^{*} \\
(149)\end{array}$ \\
\hline Treatment control & $\begin{array}{l}-.35^{*} \\
(160)\end{array}$ & & $\begin{array}{l}-.22^{* *} \\
(161)\end{array}$ & & $\begin{array}{l}.31^{*} \\
(149)\end{array}$ \\
\hline Identity & $\begin{array}{l}.43^{*} \\
(159) \\
\end{array}$ & & $\begin{array}{l}.31 * \\
(160) \\
\end{array}$ & & $\begin{array}{l}.55^{*} \\
(148) \\
\end{array}$ \\
\hline Concern & & $\begin{array}{l}.33 * \\
(161) \\
\end{array}$ & & $\begin{array}{l}.36 * \\
(162) \\
\end{array}$ & $\begin{array}{l}.39 * \\
(150) \\
\end{array}$ \\
\hline Coherence & & $\begin{array}{l}-16^{*} \\
(161)\end{array}$ & & $\begin{array}{l}-.10 \\
(162)\end{array}$ & $\begin{array}{l}-.09 \\
(150)\end{array}$ \\
\hline $\begin{array}{l}\text { Behavioural } \\
\text { disengagement }\end{array}$ & & $\begin{array}{l}.56^{*} \\
(155)\end{array}$ & & $\begin{array}{l}.50 * \\
(156)\end{array}$ & $\begin{array}{l}.60^{*} \\
(151)\end{array}$ \\
\hline Self-blame & & $\begin{array}{l}.47^{*} \\
(155)\end{array}$ & & $\begin{array}{l}.57^{*} \\
(156)\end{array}$ & $\begin{array}{l}.60^{*} \\
(151)\end{array}$ \\
\hline Substance use & & $\begin{array}{l}.27^{*} \\
(155) \\
\end{array}$ & & $\begin{array}{l}.21^{*} \\
(156) \\
\end{array}$ & $\begin{array}{l}.31 * \\
(151)\end{array}$ \\
\hline
\end{tabular}

This article is protected by copyright. All rights reserved. 


\begin{tabular}{|l|l|l|l|l|l|}
\hline Denial & & $.24^{*}$ & & $.33^{*}$ & $.28^{*}$ \\
& $(155)$ & $(156)$ & $(151)$ \\
\hline
\end{tabular}

a. ${ }^{*} p<.05$

b. bold text indicates variables that were considered for inclusion as predictor variables in the linear regression models.

Pearson's $r$ correlations $(R)$ were used if the items being assessed for correlation were both normally distributed and Spearman's rho $(\rho)$ correlations were used if one or more of the items being assessed for correlation were not normally distributed.

Table 2

Demographic information and comparison with UK population-based sample

\begin{tabular}{|l|l|l|}
\hline & Present study sample, $\mathrm{n}(\%)$ & $\begin{array}{l}\text { UK population-based } \\
\text { sample in Ogdie et al. 2013, } \\
\mathrm{n}(\%)\end{array}$ \\
\hline Sex & & \\
\hline Male & $40(22.3)$ & $4588(50.7)$ \\
\hline Female & $138(77.1)$ & $4457(49.3)$ \\
\hline Missing data & $1(0.6)$ & $0(0)$ \\
\hline Age (years) & & \\
\hline $18-29$ & $15(8.4)$ & $669(5)$ \\
\hline $30-39$ & $32(17.9)$ & $1735(16)$ \\
\hline $40-49$ & $66(36.8)$ & $2109(28)$ \\
\hline $50-59$ & $55(30.8)$ & $2207(36)$ \\
\hline $60-69$ & $9(5)$ & $1408(31)$ \\
\hline $70-80$ & $2(1.1)$ & $714(21)$ \\
\hline $80-90$ & $0(0)$ & $203(11)$ \\
\hline Total & $179(100)$ & $9045(100)$ \\
\hline
\end{tabular}

This article is protected by copyright. All rights reserved. 
Table 3

Outcome and Predictor Variables

\begin{tabular}{|l|l|l|l|l|l|l|l|}
\hline Variable & $\mathrm{N}$ & $\mathrm{M}$ & $\mathrm{Md}$ & $\mathrm{SD}$ & $\mathrm{IQR}$ & Min. & Max. \\
\hline Outcome variables & & & & & & & \\
\hline Depression & 170 & 8.14 & & 4.21 & & 0 & 19 \\
\hline Anxiety & 171 & 9.08 & & 4.64 & & 0 & 20 \\
\hline Quality of Life & 151 & & 13.00 & & 9.00 & 0 & 20 \\
\hline Disease severity & & & & & & & \\
\hline PsO Severity & 142 & & 3.00 & & 10.13 & 0 & 38 \\
\hline PsA Severity & 170 & 3.13 & & 1.00 & & 1 & 5 \\
\hline Illness Beliefs & & & & & & & \\
\hline Consequences & 163 & & 7.00 & & 2.00 & 1 & 10 \\
\hline Timeline & 163 & & 10.00 & & 0.00 & 5 & 10 \\
\hline Personal control & 163 & & 3.00 & & 3.00 & 0 & 10 \\
\hline Treatment control & 163 & 5.28 & & 2.41 & & 0 & 10 \\
\hline Identity & 162 & 6.91 & & 1.92 & & 2 & 10 \\
\hline Concern & 164 & & 7.50 & & 4.00 & 0 & 10 \\
\hline Coherence & 164 & & 7.00 & & 3.75 & 0 & 10 \\
\hline Coping Strategies & & & & & & & \\
\hline Behavioural disengagement & 158 & & 3.00 & & 2.00 & 2 & 8 \\
\hline Self-blame & 158 & & 4.00 & & 3.00 & 2 & 8 \\
\hline Substance use & 158 & & 2.00 & & 2.00 & 2 & 8 \\
\hline Denial & 158 & & 2.00 & & 1.25 & 2 & 8 \\
\hline Note. N number of & & & & & & \\
\hline
\end{tabular}

Note. $\mathrm{N}=$ number of participants, $\mathrm{M}=$ mean, $\mathrm{Md}=$ median, $\mathrm{SD}=$ standard deviation, $\mathrm{IQR}=$ inter-quartile range

This article is protected by copyright. All rights reserved. 
Table 4

Final hierarchical linear regression models of factors predicting depression, anxiety and quality of life in people with PsA

\begin{tabular}{|l|l|l|l|l|}
\hline & $\begin{array}{l}\text { Unstandardised Beta } \\
(95 \% \mathrm{CI})\end{array}$ & $\begin{array}{l}\text { Standardise } \\
\mathrm{d} \text { Beta }\end{array}$ & $\begin{array}{l}\mathrm{F} \text { for } \\
\text { change in } \\
\mathrm{R}^{2}(\mathrm{df})\end{array}$ & $\begin{array}{l}\mathrm{R}^{2} \\
\text { change }\end{array}$ \\
\hline Model predicting depression: & & & & \\
\hline Step 1 & & & $21.44^{*}(2)$ & 0.24 \\
\hline PsA severity & $1.99(1.36,2.61)$ & $0.47^{*}$ & & \\
\hline Psoriasis severity & $0.05(-0.03,0.13)$ & 0.10 & & \\
\hline Step 2 & & & $25.87^{*}(3)$ & 0.37 \\
\hline PsA severity & $0.86(0.15,1.58)$ & 0.21 & & \\
\hline Psoriasis severity & $0.05(-0.02,0.12)$ & 0.10 & & \\
\hline Beliefs about consequences & $0.84(0.52,1.17)$ & $0.44^{*}$ & & \\
\hline Step 3 & & & $29.43^{*}(4)$ & 0.47 \\
\hline PsA severity & $0.69(0.03,1.35)$ & 0.16 & & \\
\hline Psoriasis severity & $0.02(-0.05,0.09)$ & 0.04 & & \\
\hline Beliefs about consequences & $0.58(0.27,0.90)$ & $0.31^{*}$ & & \\
\hline Behavioural disengagement & $0.94(0.58,1.31)$ & $0.37^{*}$ & & \\
\hline Model predicting anxiety: & & & & \\
\hline Step 1 & & & $6.85+(2)$ & 0.09 \\
\hline PsA severity & $1.20(0.46,1.95)$ & $0.26+$ & & \\
\hline Psoriasis severity & $0.08(-0.01,0.17)$ & 0.14 & & \\
\hline Step 2 & & & $22.32^{*}(3)$ & 0.33 \\
\hline PsA severity & $0.49(-0.19,1.16)$ & 0.11 & & \\
\hline Psoriasis severity & $0.04(-0.04,0.12)$ & 0.07 & & \\
\hline Self-blame & $1.26(0.91,1.62)$ & $0.52^{*}$ & & \\
\hline Model predicting quality of life: & & & & \\
\hline Step 1 & & & & \\
\hline PsA severity & $2.95(2.18,3.72)$ & $0.55^{*}$ & & \\
\hline Psoriasis severity & $0.05(-0.04,0.15)$ & 0.08 & & \\
\hline Step 2 & & & & \\
\hline PsA severity & $1.13(0.31,1.94)$ & $0.21+$ & & \\
\hline Psoriasis severity & $0.05(-0.03,0.13)$ & 0.08 & & \\
\hline Beliefs about consequences & $1.37(1.00,1.74)$ & $0.56^{*}$ & & \\
\hline Step 3 & & & & \\
\hline PsA severity & $0.58(-0.11,1.26)$ & 0.11 & & \\
\hline Psoriasis severity & $0.02(-0.48,0.87)$ & 0.03 & & \\
\hline Beliefs about consequences & $0.83(0.50,1.16)$ & $0.34^{*}$ & & \\
\hline Depression & $0.64(0.48,0.80)$ & $0.50^{*}$ & & \\
\hline
\end{tabular}

a. ${ }^{*} p<.001,+p<.01$

This article is protected by copyright. All rights reserved. 